\section{REMARKS ON TWO CASES OF SINGLE KIDNEY.}

By P. W. MACDONALD, M.B. \& C.M. ABERD.,

DEPUTY MEDICAL SUPERTNTENDENT, DORSET COUNTY ASYLUM.

CASEs of congenital absence of one kidney are comparatively rare. Mr. Henry Morris, in an address before the Medical Society of London, said:- "Out of 8068 postmortem cases there were but two instances of congenital absence, and one only of congenital atrophy, of the kidney." To have met with two cases in less than one hundred necropsies has, judging from recorded cases, been the experience of none, and I have thought the following remarks might be of interest to those who give their special attention to the surgery of the kidneys.

The first case I met with was in 1881 . The subject was a male patient suffering from epileptic dementia. He died on April 27 th, and a necropsy was made forty-eight hours after death. The brain, lungs, and heart were found to be, as far as the naked eye could discern, normal. Liver large and congested; capsule adherent. Cut surface shiny and dark-coloured; blood oozed out; whole organ soft and

FIG. 1.

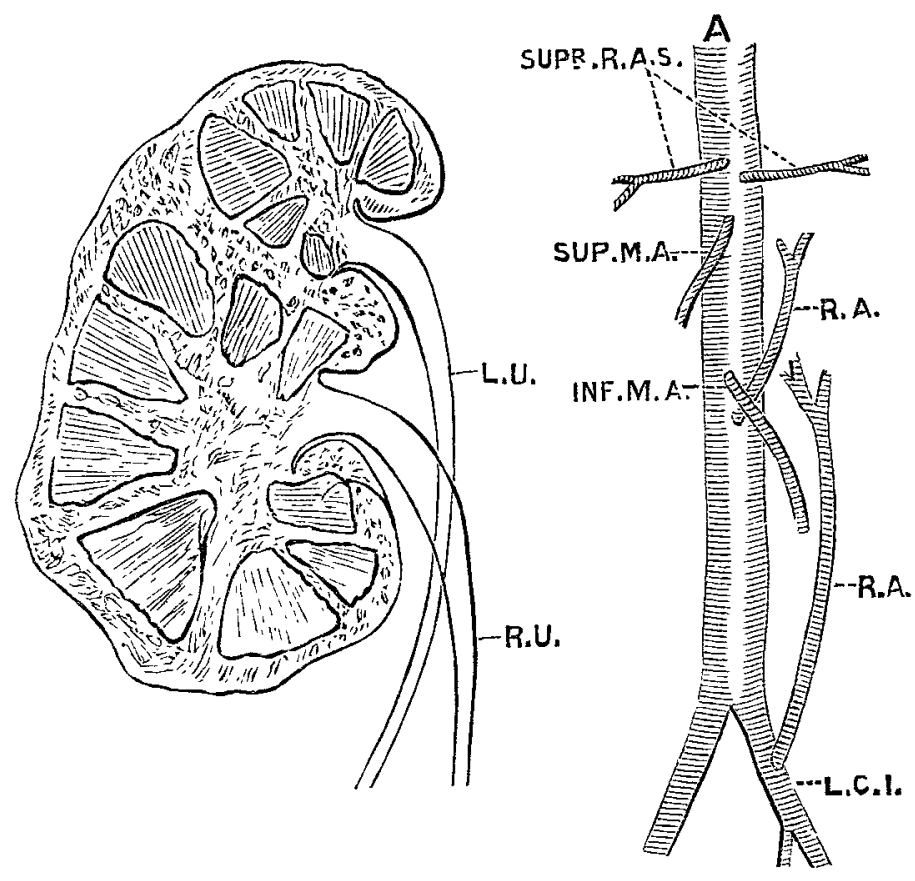

probably fatty. Spleen normal. The liver and spleen being removed, I then proceeded to remove the kidneys, and found they were absent from where they normally ought to have been. Reflecting the mesentery and small intestines, one large kidney was found lying on the spinal column opposite the second, third, and fourth lumbar vertebræ. (Fig. 1.) It was enveloped in a natural capsule. It was large, weighing over $11 \frac{1}{2} \mathrm{oz}$, and somewhat irregularly shaped. Vascular supply abnormal and large. One branch had its origin from the aorta, and a second one from the left common iliac artery. The branch from the iliac artery, which was the larger, entered at the normal pelvis, and the one from the aorta at the second or smaller pelvis. There were two ureters. One came from the normal pelvis of the kidney, the other from a sort of second pelvis at the upper end of the kidney. Both entered the bladder normally. The one from the smaller pelvis passed behind the one from the normal pelvis, and entered the bladder on the right side (as right ureter). The other ducts and glands in connexion with the prostate were normal. There were two supra-renal capsules, one situated on each side of the eleventh dorsal vertebra, therefore quite unconnected with the kidney. Pelvic organs normal.

The second case was that of a female patient, who was admitted into this asylum on Aug. 16th, 1883, and died on Dec. 3rd, 1883. This patient was also the subject of epilepsy. At the necropsy, made twenty-four hours after death, the body was emaciated, and there was slight odema of the left leg. Head : Thickening and opacity of the arachnoid over the frontal lobes and atrophy of the left superior frontal convolution. Pia mater easily removed. No apparent congestion. Heart large, and muscular structure pale; valves closed. Both lungs were studded with caseous nodules, and there were several rather large cavities in the left lung. There were pleuritic adhesions. The liver was soft and pale. On section, there were signs of commencing fatty changes. The capsule showed whitish patches. The spleen was normal. Intestines normal and no ulceration. On proceeding to remove the kidneys, no trace of the right kidney or ureter could be found. The left lay in its normal position; was large, weighing overnine ounces. (Fig.2.) The suprarenal capsules were normal. There was one ordinary-sized ureter, which entered the bladder on the left side. There were two renal arteries; one large one coming off from the aorta below the superior mesenteric artery, and a second smaller one an inch below the larger. The larger one gave a branch to the left supra-renal capsule. The right capsule received a branch from the aorta. The kidney was congested, but not otherwise diseased. Pelvic organs normal.

In neither case was it known during life that there was only one kidney present - a fact easily understood when it is stated that in the first case the patient was an epileptic dement, and at no time of his residence in the asylum had he shown any symptom of kidney mischief, and at last died from

\section{Fig. 2.}

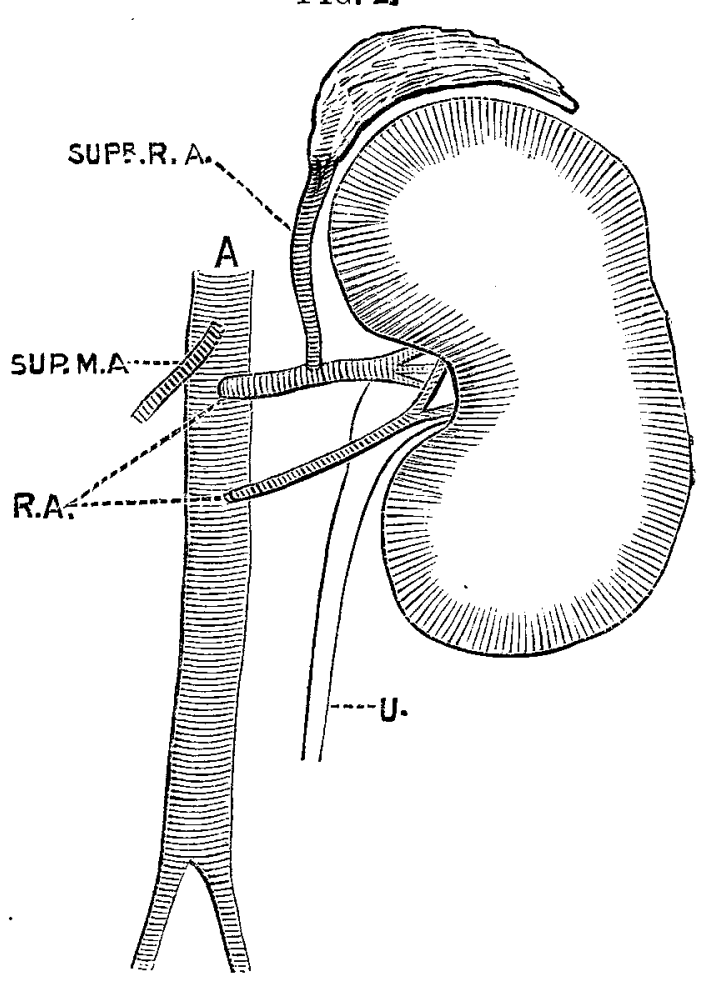

general decay. The subject of the second case (female) was also suffering from epilepsy with maniacal symptoms, and after a short residence in the asylum succumbed to one of the most dire diseases, phthisis. The cedema of the left leg in this case was due to an enfeebled and embarrassed circulation. It will thus be seen that there was at no time any necessity to make an external examination of the kidneys, and consequently the fact remained unknown till met with on the post-mortem table. The interesting points are the abnormal site of the kidney with its two ureters, in one case, and the large and abnormal arterial supply in both. There would have been much difficulty in arriving at even a probable diagnosis as to the site of the kidney, in the first case, had need arisen to map out the kidney on the living subject, a proceeding which is at no time attended with certainty; for Mr. Luther Holden says : "I have never succeeded in satisfying myself that I have distinctly felt its rounded lower border in the living subject, nor even in the dead.". As already mentioned, the kidney was large and irregular. On section it seemed to be one large kidney with a smaller one joined on to its upper end. The smaller pelvis had separate and distinct pyramids, and there was a rather thick cortical layer between them and those of the larger or normal pelvis. The arterial supply was abnormal in both cases, and the branch supplied by the left 
common iliac artery would have caused much annoyance in any operation on that artery or in its immediate neighbourhood.

Numerous cases of the congenital absence of one kidney have been met with and reported. Mr. Jonathan Hutchinson, in a clinical lecture ${ }^{3}$ delivered at the London Hospital, mentions a case and draws attention to the dangers that may arise in such cases from suppression of urine by renal calculi or any other untoward event. Mr. Gubbin ${ }^{4}$ reports a case of complete absence of the left kidney and suprarenal capsule, and quotes a series of cases collected by Dr. Brenner in 1838. ${ }^{.}$Dr. Brenner states that in a third of his cases there was malformation or arrest of development in one or other of the genital organs. Mr. Thomas Wilmot ${ }^{6}$ mentions a case of single kidney, and states that the apparent cause of death was the secondary formation of an abscess in the kidney. In 1878 Beumer collected a series of cases, and drew attention to the effect of the absence of one kidney on the sexual passions. In the literature on the subject to which I have had access I fail to find a reported case of single kidney with two ureters. Notwithstanding that such cases are rare, it is, nevertheless, necessary in these days of advanced abdominal surgery to recall and bear in mind such important abnormalities, for a timely thought in this direction might save both surgeon and patient from unpleasant recollections.

Dorset County Asylum.

\section{ON A URAL EXOSTOSES.}

BY GEORGE P. FIELD, M.R.C.S., AURAL SURGEON TO ST. MARY'S HOSPITAL.

THE following four cases of exostosis in the auditory canal have been recently under treatment by me. I now place them on record-first, because they afford further demonstration of certain important facts which I have already insisted on-namely, that ivory aural exostoses can be successfully removed, not only without great risk, but with decided benefit to the patient, relieving him sometimes of grave cerebral symptoms, and, as a rule, completely restoring the power of hearing; secondly, because I find that it is still customary to inform persons afflicted with these growths that they must make up their minds to endure permanent deafness, the dangers of any possible operation for their relief being such as to render it entirely unadvisable. How contrary to actual experience is this latter statement has been well shown by my first case, that of Dr. G. Mof Waterford, operated on in October, 1877, and described in THE LANCET for July 20 th of the following year. As I have there remarked, the patient, when I first saw him, was suffering from extreme depression of spirits; for, knowing each of his ears to be completely obstructed by a dense bony tumour, he felt himself to be for life debarred from the pleasures of society. The result of operation in his case was thorough restoration of hearing, which now, after the lapse of eight years, remains as good as ever.

The origin of ivory aural exostoses has been repeatedly attributed to gout, rheumatism, or syphilis, alone or combined; but, as I first pointed out in the discussion of my earliest case, a certainly far more general cause is a chronic inflammation of the walls of the external meatus, such as might.be produced by habitual sea-bathing. The Hawaiian islanders, as readers of works of travel are aware, are practically amphibious; and Professor Wyman has directed attention to the significant frequency of ivory excstoses in the external auditory meatus of their crania. The four cases that I hare operated on during the past three months, I have been interested to find, afford evidence of one and the same exciting cause-persistent sea-bathing. A former opinion of mine, that hereditary predisposition might be excluded from the probable sources of ivory aural exostoses, I have had occasion to modify to some extent; for one of my most recent patients is a younger brother of my first case, and suffered in an exactly similar way from exostoses in both ears, though happily, unlike him, requiring only one operation for their extirpation, instead of repeated treat-

3 THE LANCET, vol. ii., 1874, p. 1

4 British Medical Journal, vol. i., 1883, p. 115.

6 British Medical Journal, vol. ii., 1883, p. 1014. ment occupying altogether seven hours; it must, however, be noted, that both patients had for years been accustomed to bathing in the sea three or four times a day. In hospital practice 1 have, as others, remarked, the absence of instances of ivory aural exostosis, whereas the softer growths are not infrequent. Seemingly another peculiar feature in connexion with the disease is that in certain districts it is commoner than in others. Thus, I have had four cases from Waterford, three from Ipswich, several from the south of Ireland, and one each from Hull and West Hartlepool, \&c. The operation of drilling the tumours with the American dental engine, as first suggested by Dr. Arthur Mathewson of New York, I have more than once described. ${ }^{\mathrm{I}}$ For further information as regards the varieties, mode of occurrence, and characteristics of osseous tumours of the meatus, $I$ would refer to the third edition of $\mathrm{my}$ book, p. 69 .

I will now proceed to give, as briefly as possible, an account of my four most recent cases.

The first is that of Mr. W. G. D. G--, aged forty-six, a gentleman living near Waterford, whose history I do not think I can do better than give in his own words, as follows: "I was first troubled by an abscess in my right ear in Sept. 1883, the effect, probably, of sea-bathing, and the frequent use of an old spring-board some beggar put up on Kelly's Rocks, evidently for the benefit of the medical profession. The abscess caused deafness for some three or four weeks, but was eventually cured by the application by Dr. O'Farrell of a solution of caustic. In October, not being satisfied with the feel of my ear, I consulted Mr. Fitzgerald in Dublin, who said the passages in both ears were much contracted, and I might eventually have to get them operated on. He prescribed a lotion, which I used for some time, and hearing came back all right. In 1884 I was yachting from the middle of May till the end of September, and took a header or two off the main boom each morning. At the end of the season I was again troubled with an abscess, this time in the left ear, causing deafness. At the end of November I consulted Mr. Field, who diagnosed double ivory exostosis. After the removal of a polypus from the left ear its hearing returned but the exostoses had now so increased that, as soon as I could spare time, early in February, I had the worse ear, the left, drilled, the operation lasting sixty-five minutes. In consequence of leaving London before the ear was sufficiently healed, it became filled with granulations, which gave much trouble to get rid of from the beginning till near the end of March. On the 9th of that month the other, or right, ear was operated on, chloroform being administered for one hour and ten minutes, and in it also hearing is now (April 11th) nearly restored." I may add to this account that by April 25th audition was quite perfect in the left ear, and well nigh so in the right.

The next case is that of Mr. S. W-, aged twenty-six, sent to consult me by Mr. Swannick, of West Hartlepool, in Nov. 1883. He was then suffering from slight deafness of both ears, caused by the presence of exostoses, which I suggested should be removed if they gave rise to any further trouble. When, in Feb. 1885, he came back to me, I found the left external meatus considerably lessened in calibre, and the right almost completely blocked by the exostoses. I had now no hesitation in recommending early extirpation of the growths. On Feb. $24 \mathrm{th}$, chloroform having been administered, 1 succeeded, after fifty minutes' labour, in effectually drilling through the obstruction in the right ear. The patient recovered well from the operation, and had one or two returns of his nocturnal giddiness during the next few days. My colleague, Dr. Broadbent, who saw him, kindly gave me the following opinion of his case:- "Mr. S. W-'s attacks may be conveniently called epileptiform, but they have not the character of epilepsy proper, inasmuch as there appears to be neither convulsion nor loss of consciousness. I am disposed to fear that they differ in a more important respect, and that they are attended with danger to life. I do not think, however, that, like some of the cases recently reported, the attacks are due to the slow pulse with which they are accompanied. In my opinion they are cerebral in origin, and the retardation of the pulse is secondary. I did not find much on examination which threw light on the case. The optic discs were small and pink and without sharp outlines; and the retinal veins were large; but there was no neuritis. The right temporal artery was more conspicuous than the left, and pulsation

1 See ThE LAxcre, July 20th, 1880, and April 1st, 1882, British Medienl Journal, Nov. 2tth, 1883; also see Roosa's work, sixth edition, p. 485 . 